FERNÁNDEZ, José Ángel. “Análisis crítico del discurso y criminología.

Una aproximación interdisciplinar"

Polít. crim. Vol. 8, Nº 16 (Diciembre 2013), Art. 4, pp. 472-499.

[http://www.politicacriminal.cl/Vol_08/n_16/Vol8N16A4.pdf]

\title{
Análisis crítico del discurso y criminología. Una aproximación interdisciplinar
}

\author{
José Ángel Fernández Cruz* \\ Profesor de Derecho penal y Criminología \\ Facultad de Ciencias Jurídicas y Sociales de la Universidad Austral de Chile \\ josefernandez@uach.cl
}

\section{Resumen}

El Análisis Crítico del Discurso constituye una provechosa herramienta analítica para comprender el fenómeno de la criminalidad y los medios de control social. Sus aspectos más relevantes radican en el análisis de las estructuras y estrategias del texto y del habla y sus relaciones con los contextos políticos y sociales. En la Nueva Era de la Información, la realidad discursiva debe constituir un aspecto central en el desarrollo de las Ciencias penales.

Palabras clave: Análisis crítico del discurso, criminología crítica, política criminal.

\begin{abstract}
Critical Discourse Analysis is useful analytical tool to understand the phenomenon of crime and criminal justice systems. Its most relevant feature lies in the analysis of structures of text and speech and its relationships with public and social contexts. In the New Era of Information, Critical Discourse Analysis should be a main central issue in Criminology and Criminal Justice.
\end{abstract}

Key words: Critical discourse analysis, critical criminology, criminal justice.

\section{Introducción}

El pensamiento crítico ha puesto de manifiesto la importancia del discurso como un medio de dominación social. ${ }^{1}$ El acceso a formas específicas de discurso, por ejemplo, en la política, los medios de comunicación o la ciencia, constituye en sí mismo un recurso de

\footnotetext{
* El presente estudio constituye una profundización de un estudio previo presentado para su evaluación en la Revista de Estudios Filológicos de la Universidad Austral de Chile, pendiente de publicación. En este estudio ampliado se ha introducido un capítulo sobre el tratamiento del discurso por parte de la Criminología y la Teoría de la Comunicación. Quisiera agradecer al Prof. VAN DIJK por los comentarios, sugerencias y críticas a este estudio. Estos comentarios serán citados como VAN DIJK, Teun A., Comentarios a este estudio (inédito).

${ }^{1}$ Habermas, desde su concepción consensualista del discurso, no duda en afirmar que el "lenguaje es también un medio de dominación y una fuerza social”, HABERMAS, Jürgen, Conocimiento e interés, Madrid: Taurus, 1992 , p. 259.
} 
FERNÁNDEZ, José Ángel. “Análisis crítico del discurso y criminología.

Una aproximación interdisciplinar"

poder. El discurso-poder significa, por último, que aquellos grupos que controlan los discursos más influyentes tienen también más posibilidades de controlar las mentes y acciones de los otros. ${ }^{2}$ Esta dominación discursiva se representa en las diferentes fases de incriminación penal e, incluso con una mayor intensidad, ya que el derecho penal constituye una de las manifestaciones más evidentes e intensas de nuestro sistema social discriminatorio.

En el presente estudio pretendo llamar la atención sobre la importancia del discurso a la hora de afrontar, desde una perspectiva crítica, tanto el fenómeno de la criminalidad, como las medidas penales de control social. Si bien es cierto que la criminología ha venido estudiando el discurso a través de los medios de comunicación y la opinión pública, no ha prestado especial atención al análisis de los textos y otras formas de creación de significado. Como manifiesta Fairclough, los teóricos sociales han articulado sus aportes de manera abstracta, es decir, sin un análisis lingüístico de los textos. ${ }^{3}$ Este ámbito de estudio es abordado, entre otros, por los analistas del discurso.

Si queremos comprender el fenómeno de la criminalidad y del poder punitivo no basta con acudir a la realidad fáctica, sino que debemos tener presente la realidad discursiva. En caso contario, no podremos comprender y analizar fenómenos, como por ejemplo, el que el derecho penal constituya la parcela de las relaciones sociales donde se han aplicado unas mayores cotas de racionalidad, al menos, en Chile; pero, sin embargo, cuanto más se camina en este sentido, más se aleja de las construcciones discursivas compartidas por la ciudadanía. $^{4}$

En el presente artículo se realizará un estudio aproximativo del denominado Análisis Crítico del Discurso (en lo sucesivo ACD). No pretendemos abordar con profundidad este enfoque del discurso, sino mencionar aquellos aspectos que poseen una relación más directa con la política criminal y la criminología. En último término, se pretende llamar la atención sobre la necesidad de incorporar el ACD al pensamiento penal crítico y, en especial y valga la redundancia, a la criminología crítica.

Para llevar a buen puerto este objetivo; en primer lugar, mencionaremos algunas de las teorías, corrientes de pensamiento o paradigmas sociales que han influenciado en la creación y desarrollo del ACD o que, simplemente, comparten algunas de sus características; en segundo lugar, realizaremos una somera introducción de esta corriente crítica de análisis del discurso y su relaciones con la criminología y la política criminal; y, en tercer lugar, señalaremos algunas de las críticas que se han efectuado al ACD.

\footnotetext{
${ }^{2}$ VAN DIJK, Teun A., "El análisis crítico del discurso", Anthropos n 186, septiembre-octubre 1999, p. 26.

${ }^{3}$ FAIRCLOUGH, Norman, "El análisis crítico del discurso y la mercantilización del discurso público: Las universidades", Discurso y Sociedad, Vol. 2(1), 2008, p. 172.

${ }^{4}$ En el mismo sentido, VATINO, G., "Prólogo" en: MESSUTI, A., La Justicia deconstruida, Barcelona: Bellaterra, 2008, p. 12.
} 
Polít. crim. Vol. 8, № 16 (Diciembre 2013), Art. 4, pp. 472-499.

[http://www.politicacriminal.cl/Vol_08/n_16/Vol8N16A4.pdf]

\section{Una comprensión interdisciplinar del ACD.}

El ACD no es tanto una dirección o escuela sino un movimiento social de investigadores comprometidos con la lucha contra la discriminación y la desigualdad social. Su carácter interdisciplinar y los diferentes métodos de análisis utilizados imprimen una manera alternativa o complementaria de analizar la realidad social. Constituye, como veremos con posterioridad, una forma complementaria de aproximarse a la realidad criminal y al poder punitivo desde una perspectiva crítica. No obstante, el discurso de la criminalidad y del poder punitivo no ha estado ausente en las ciencias sociales. Dos disciplinas se han ocupado, de forma paralela: la propia criminología y las teorías sobre la comunicación. ${ }^{5}$ Las relaciones de estas disciplinas con el ACD son evidentes. En cuanto a la criminología, tenemos que destacar, por una parte, los estudios relacionados con la opinión pública y los medios de comunicación y, por otra, las teorías criminológicas que acuden al análisis del discurso como método de investigación, como por ejemplo, la criminología posmoderna. ${ }^{6}$ Respecto a las teorías de la comunicación, el análisis del discurso constituye también uno de sus métodos de investigación. ${ }^{7}$

Las teorías de la comunicación y la criminología, como ciencias sociales de naturaleza claramente interdisciplinar, ha compartido históricamente los mismos paradigmas, teorías y aproximaciones científicas y, por ende, han desarrollado y compartido similares objetos de investigación. ${ }^{8}$ Como veremos a continuación, este acervo científico también concurre en mayor o menor medida en el ACD. ${ }^{9}$

\subsection{La teorización de la sociedad de masas.}

La teoría de la sociedad de masas estudia el fenómeno de las grandes concentraciones de población que surgieron como consecuencia de los procesos de industrialización y urbanización que acaecieron a partir de la Gran Guerra. Esta teoría entiende que ha aumentado, como consecuencia de estos procesos, el sentimiento de vulnerabilidad en esta nueva forma de sociedad. Los individuos estructurados en comunidades fragmentadas se han transformado en una masa desligada de la libertad individual, alejada de los valores morales y éticos obtenidos del trabajo y la religión, y caracterizada por su apatía política y por un gusto por la cultura del entretenimiento. Las masas son vistas como ignorantes y susceptibles de ser manipuladas, potencialmente indisciplinadas y propensas a la violencia. Ante esta situación, los medios de comunicación suplen, en cierta media, esta falta de

\footnotetext{
${ }^{5}$ Cuatro vertientes han tomado la teoría de la comunicación: (a) La investigación de las audiencias; (b) la comunicación de grupos y sus efectos entre los miembros de los mismos; (c) el efecto del contenido de la comunicación y (d) el cambio de actitudes a través de la comunicación.

${ }^{6}$ MILOVANOVIC, Dragan, "Postmodernism", en: McLAUGHLIN, Eugene; MUNCIE, John, (Eds.), The Sage Dictionary of Criminology, Sage Publications Ltd., $2^{\mathrm{a}}$ Ed., 2006, p. 308.

${ }^{7}$ Véase, con mayor profundidad, VAN DIJK, Teun A., "Critical Discourse Analysis", en: TANNEN, D.; SCHIFFRIN, D. y HAMILTON, H. (Eds.), Handbook of Discourse Analysis, Oxford: Blackwell, 2001, p. 359.

${ }^{8}$ YVONNE, Jewkes, Media \& Crime, $2^{\text {a }}$ Ed., Sage Publications Ltd., 2011, p. 9.

${ }^{9}$ El presente apartado ha tomado como referencia la sistematización realizada en el capítulo segundo de la monografía de Jewkes Yvonne, salvo el dedicado a los estudios sociocognitivos. YVONNE, Media \& Crime, cit. nota $\mathrm{n}^{\circ} 8$, pp. 6-40.
} 
FERNÁNDEZ, José Ángel. “Análisis crítico del discurso y criminología.

Una aproximación interdisciplinar"

cohesión social que, a la vez, les otorga un enorme poder para controlar los pensamientos y emociones de los individuos. ${ }^{10}$

La influencia de la teoría de la sociedad de masas en el ACD se manifiesta en un doble sentido. Por una parte, el ACD asume que los medios de comunicación, como soporte de los principales géneros discursivos, inciden en los comportamientos y acciones de los receptores del discurso; y por otra, parte, parece compartir esta cierta perspectiva negativa de la condición humana, susceptible de asumir con cierta facilidad influencias externas.

\subsection{Las teorías de la comunicación conductistas: los efectos de los medios de comunicación.}

Los denominados "grandes persuasores" constituyen el ejemplo paradigmático de que la acción humana responde principalmente a los estímulos del medio y que esta relación causa-efecto puede ser determinada y observada. ${ }^{11}$ Las teorías de la comunicación conductistas entienden que los efectos producidos por los medios de comunicación pueden tomar tres formas. La primera, la corrupción de la moral y de las normas de decencia y urbanidad; la segunda, la merma en la formación cultural e intelectual de los ciudadanos; y la tercera, de acuerdo con la izquierda intelectual, la manipulación de los ciudadanos conforme a los intereses de los más poderosos. Esta visión causalista y negativa de los medios de comunicación tuvo su máxima expresión en los regímenes totalitarios de mediados del Siglo XX. ${ }^{12}$

No obstante, los primeros estudios conductistas fueron cuestionados, entre otras razones, por reduccionistas -ya que acortaban la complejidad de la conducta humana a un único factor-y por su percepción negativa de la sociedad. Por el contrario, se debe tener presente la sutileza de la información, las diferentes características e identidades de las audiencias y el especial contexto social y cultural en el que se enmarca un determinado medio de comunicación. Además, no debemos olvidar el hecho de que la audiencia puede determinar el contenido de los medios de comunicación.

No obstante, en determinados medios de comunicación y poderes públicos continúan teniendo un especial predicamento las visiones reduccionistas del conductismo, especialmente, respecto de crímenes violentos cometidos por menores que han sido expuestos a películas o videojuegos violentos. La denominada teoría de la copia del crimen

\footnotetext{
${ }^{10}$ BENETT, Tony, "Theories of the media", theories of society, en: GUREVITCH, M. et al (Eds.), Culture, Society and the Media, London: Methuen, 1982, p. 31-32.

${ }^{11}$ Así, por ejemplo, en el conocido experimento realizado en la Universidad de Stanford en 1950 a un grupo de niños se comprobó que, tras exhibirles imágenes de cierta violencia y entregarles unos muñecos para jugar con ellos, mostraron un comportamiento más agresivo con los muñecos respecto de otros grupos de niños a los cuales no les enseñaron estas imágenes. YVONNE, Media \& Crime, cit. nota $\mathrm{n}^{\circ}$ 8, p.13.

${ }^{12}$ Otra muestra fue la conocida retrasmisión radiofónica de Orson Wells sobre la Guerra de los Mundos en la noche de Halloween de 1938. No obstante, este suceso como muestra de los importantes efectos que pueden producir los medios de comunicación fue criticado de cierto reduccionismo. Así, por ejemplo, no se tomó en cuenta los efectos psicológicos de la Gran Depresión sobre los ciudadanos estadounidenses, propensos a buscar líderes que les guiaran para salir de la crisis económica y social que estaban sufriendo; ni tampoco la inminente guerra en Europa y la posible invasión de fuerzas extranjeras en territorio Estadounidense. YVONNE, Media \& Crime, cit. nota ${ }^{\circ} 8, \mathrm{p} .14$.
} 
que pretende sustentarse en esta relación causa-efecto, en último término se fundamenta en el sentido común, es decir, en una percepción fragmentaria de la realidad.

El ACD, como veremos con posterioridad a la hora de estudiar sus relaciones con el pensamiento crítico y el posmodernismo, mantiene un cierto rechazo al positivismo. A lo anterior, debemos añadir que parte de sus analistas y, en especial Van Dijk, critican abiertamente la aplicación de las teorías conductistas al análisis del discurso. Así, tomando como referencia al autor holandés, en primer lugar, niega que las situaciones o eventos sociales ejerzan una influencia directa e inmediata sobre el uso del lenguaje; por el contrario, entiende que las estructuras sociales y discursivas son estructuras diferentes, ya que si existiera una relación causal entre ambas, los usuarios del lenguaje en una misma situación social dirían o escribirían cosas muy parecidas. El punto de conexión entre estas dos estructuras está constituido por las interpretaciones (subjetivas) de los participantes conforme a su biografía individual y social, definidas como modelos de contexto. ${ }^{13}$

La segunda crítica y como consecuencia de la anterior, radica en la falacia de la observabilidad, según la cual la acción, el texto y la conservación son perceptibles por los sentidos, pero no así las mentes de los usuarios del lenguaje. No obstante, los usuarios de lenguaje participan en los eventos comunicativos con una enorme cantidad de conocimientos compartidos socialmente, con experiencias, planes, objetivos, opiniones y emociones. No solo, por tanto, se debe analizar lo que resulta observable del evento comunicativo, sino también las mentes de los interlocutores. En palabras del autor citado, "la porción observable de aquello que se dice o hace es solo la punta del iceberg de un evento comunicativo". 14

En todo caso, podemos afirmar que en el ACD subyace la idea conductista de que el discurso produce efectos, al menos mediatos, en el accionar humano y en la construcción de otros discursos, en especial, respecto de las relaciones (de poder) que se pueden determinar a través, precisamente, del análisis del discurso y el contexto asociado a él.

\subsection{La teoría de la ideología dominante.}

Sin duda, el ACD encuentra uno de sus principales antecedentes en el pensamiento marxista y, en concreto en la teoría de la "ideología dominante". Gramsci (1891-1937) desarrolló el concepto marxista de hegemonía que, a partir de los años 70 del pasado siglo, ha cobrado un papel fundamental en la teorización de cómo los medios de comunicación representan al crimen, la desviación y los medios de control social.

El concepto de hegemonía cristaliza la idea de que el ejercicio del poder sobre la vida cotidiana de los sujetos a través de la dominación cultural e institucional resulta mucho más efectiva que la coerción o el recurso a las medidas expeditivas. ${ }^{15}$ El concepto de hegemonía

\footnotetext{
13 VAN DIJK, Teun A., Sociedad y discurso: cómo influyen los contextos sociales sobre el texto y la conversación, Barcelona: Gedisa, 2011, p.10.

${ }^{14}$ VAN DIJK, Sociedad y discurso, cit. nota ${ }^{\circ} 13$, p. 11.

${ }^{15}$ Por todos, RODRÍGUEZ PRIETO, Rafael y SECO MARTÍNEZ, José María, "Hegemonía y Democracia en el Siglo XXI: ¿Por qué Gramsci?”, Cuadernos Electrónicos de Filosofía del Derecho n 15 (2007), pp.3-6.
} 
FERNÁNDEZ, José Ángel. “Análisis crítico del discurso y criminología.

Una aproximación interdisciplinar"

se refiere al proceso por el cual las clases dirigentes obtienen el consenso de la ciudadanía a través de instituciones sociales y culturales tales como la familia, la educación, el derecho y los medios de comunicación. La hegemonía es hablar, por tanto, del imaginario social compartido o, en palabras del ACD, de representaciones sociales o simbolismo colectivo. Gramsci, como gran educador que fue, comprendió la importancia de la interiorización de los valores por el imaginario colectivo a la hora de establecer las relaciones de poder y dominación.

En la actualidad, los medios de comunicación representan un papel fundamental en la consecución del consenso respecto de los valores e intereses de las clases dirigentes. Los medios de comunicación -como cualquier otra institución capitalista- pertenecen y operan en beneficio de la élite burguesa, excluyendo otros intereses opuestos o alternativos. Este consenso se ve facilitado por el hecho de que la gente toma con cierta pasividad las ideas de las clases dirigentes (falsa conciencia marxista).

Asimismo, se puede apreciar clara influencia de la teoría de la ideología dominante en la orientación prescriptiva del ACD: la disgregación de los discursos dominantes y la promoción de una alternativa ideológica.

La criminología crítica también ha acudido al concepto de hegemonía para explicar la influencia de los medios de comunicación en el tratamiento de la delincuencia y los medios de control social. La obra de Stuart Hall y sus colaboradores -Policing the Crisis: Mugging, the State and Law and Order (1978) - constituye uno de los principales estudios sobre el papel que juegan los medios de comunicación en la definición del crimen y el criminal. El nacimiento de la sociedad de la ley y el orden tiene en los medios de comunicación su principal aliado a la hora de construir un discurso populista y punitivista (de dominación) sobre la criminalidad. Respecto a los estudios sobre los medios de comunicación, debemos destacar el Grupo de Medios de la Universidad de Glasgow. Este grupo de investigación viene realizando una serie de estudios empíricos y semióticos sobre la parcialidad de los medios de comunicación en el tratamiento de la denominada "industria del conflicto". 16

El ACD asume tácita o expresamente la teoría de la ideología dominante. Así, Fairclough, uno de los fundadores del ACD, manifiesta: "una característica de mi encuadre analítico es que trata de combinar una teoría del poder basada en el concepto de 'hegemonía' de Gramsci, con una teoría de la práctica discursiva basada en el concepto de intertextualidad $(\ldots)^{\prime \prime} \cdot 17$

16 Véase en profundidad: http://www.glasgowmediagroup.org/component/option,com_frontpage/Itemid,1/ [visitado el 2.02.2013].

${ }^{17}$ FAIRCLOUGH, "El análisis crítico del discurso y la mercantilización", cit. nota n ${ }^{\circ} 3$, p. 175. También reconoce la influencia del autor italiano: VAN DIJK, Teun, Discurso, Poder y Cognición Social. Conferencias de Teun $A$ A Van http://www.discursos.org/Art/Discurso,\%20poder\%20y\%20cognici\%F3n\%20social.pdf [visitado el 23.05.20012]. 
Las críticas a la teoría de la ideología dominante se centran en la sobrevaloración de las instituciones poderosas a la hora de manipular al público. Resulta erróneo afirmar que la industria de los medios mantenga siempre una política deliberativa de manipulación y exclusión de otras formas de pensamiento. Por el contrario, la manipulación con frecuencia proviene de las propias organizaciones de comunicación de masas. Los periodistas socializan los fines y objetivos de la organización donde trabajan, respondiendo de la manera que se les espera, fruto de una presión subliminal que, en no pocas ocasiones, se muestra de manera directa y abierta. En muchas ocasiones se presta más atención a que el evento constituya una buena historia que a reproducir sesgos ideológicos externos.

Relacionado con las anteriores críticas, las teorías de la comunicación desarrollaron a partir de los años 80 una nueva metodología en el estudio de las audiencias, el denominado análisis de recepción. Parte del presupuesto de que las audiencias no están sometidas fundamentalmente a fuerzas ajenas al control individual. Por el contrario, los individuos conscientemente también usan los medios de comunicación conforme a su propia identidad, valores e ideologías. En la era de la proliferación y competencia de los medios de comunicación, sus contenidos se encuentran en mayor medida determinados por las audiencias que por las ideologías dominantes. ${ }^{18}$

A pesar de estas criticas, la teoría de la ideología dominante continúa teniendo vigencia. Así, ha sido fundamental para mostrar el menor interés de los medios de comunicación en la criminalidad de los poderosos, salvo que contenga algunas de las características que hacen que un hecho sea noticiable. Esta posición también ha sido adoptada por la denominada criminología verde a la hora de explicar los procesos de des-criminalización de las grandes corporaciones involucradas en lesiones o puestas en peligro del medio ambiente. $^{19}$

\subsection{El pluralismo: la Nueva Era de la Libertad.}

Las teorías de la comunicación y la criminología asentadas en la sociedad de masas o en el paradigma de la ideología del dominante presentan a una audiencia pasiva y vulnerable a la propaganda de los más poderosos. Por el contrario el paradigma del pluralismo tiene una visión más positiva de las audiencias y los medios de comunicación, como consecuencia de la constatación de una sociedad cada vez más plural, informada y escéptica.

El cambio acaecido en los medios de comunicación en las últimas décadas ha incidido de manera positiva en una audiencia más informada. Particularmente, el proceso de desreguralización y privatización de los medios de comunicación ha evitado la censura, más o menos, velada del Estado y ha permitido el incremento de periódicos, cadenas de televisión y radio. Pero, sin lugar a dudas, ha sido la irrupción de World Wide Web la que

\footnotetext{
${ }^{18}$ FISKE, John, "Los estudios culturales británicos y la televisión", en: ALLEN, Robert (Ed.), LONGO, Fernanda (Trad.), Channels of discourse. Television and contemporary criticism. North Carolina, University of North Carolina Press, 1987, pp. 1-12. http://www.catedraa.com.ar/corporativa/archivos/FISKE-estudiosculturales.pdf [visitado el 15.05.2012].

19 RUGGIERO Vincenzo y SOUTH, Nigel, "Green Criminology and Dirty Collar Crime", Criminal criminology, vol. 18, ${ }^{\circ} 4$ (2010), pp. 251-262.
} 
FERNÁNDEZ, José Ángel. “Análisis crítico del discurso y criminología.

Una aproximación interdisciplinar"

una cambio de paradigma en el acceso y formación de la información, que -según los partidarios de esta corriente de pensamiento- ha generado una Nueva Era de la Libertad. ${ }^{20}$

Una de las manifestaciones de la nueva sociedad pluralista la encontramos en la concurrencia -junto a los definidores primarios (políticos, jefes de policía, editores de periódicos, etc.) - de los denominados "definidores de oposición"; ciudadanos que, con visiones diferentes a los comentaristas oficiales, tienen cada vez más voz en los medios de comunicación. Su mayor acceso a los medios de comunicación hace que los poderes públicos se muestren más permeables a posiciones divergentes o alternativas.

La principal crítica realizada al paradigma pluralista radica en su excesivo idealismo. Si bien teóricamente pueden asumirse sus presupuestos teóricos y que en general los medios de comunicación tienden a ser más pluralistas, tampoco debemos olvidar que la mayoría de los medios de comunicación -salvo Internet- están controlados por un puñado de hombres blancos. Además, no debemos dejar en el tintero que la privatización de los medios puede expulsar a aquellos que no pueden pagar su acceso.

A lo anterior debemos añadir, la dura competencia entre los medios de comunicación como consecuencia del proceso de desregularización y privatización- ha derivado en un periodismo fragmentado, donde apenas se toma en cuenta el contexto donde se produce la noticia. Un modelo de medios de comunicación estructurado en el mercado se ve amenazado por la tentación de acudir al mero sensacionalismo como medio para mantener la atención del público y cumplir así con los objetivos publicitarios. A nadie le resulta extraño el privilegio que se otorga a los índices de audiencia sobre la calidad del análisis y el debate. En otras palabras, un medio de comunicación pluralista no genera siempre información pluralista.

Tampoco debemos echar en saco roto los conflictos que forzosamente se producen en las denominadas sociedades multiculturales que pueden derivar en la creación de discursos racistas y de exclusión. ${ }^{21}$ Estas críticas se presentan de manera especial en el tratamiento de la criminalidad por parte de los medios de comunicación. Mientras se constata un incremento del interés de la audiencia por los hechos violentos visualmente impactantes, no existe evidencia de una participación de individuos y colectivos que permitan conocer los sus diferentes contextos políticos, sociales y culturales. ${ }^{22}$

El ACD también tiene presente las nuevas formas de conflicto que se dan en las sociedades democráticas (pluralistas). Como manifiesta Van Dijk constituye una necesidad imperativa que el ACD estudie la compleja interacción de los grupos dominantes, disidentes y opositores y sus discursos dentro de la sociedad, con el fin de esclarecer las variantes contemporáneas de la desigualdad social. ${ }^{23}$ Por último, podemos encontrar un punto en común con el paradigma pluralista en la dimensión prescriptiva del ACD que aboga por una

\footnotetext{
${ }^{20}$ MACNAIR, B., The Sociology of Journalism, Londres: Arnold, 1998, pp. 45 y ss.

${ }^{21}$ Por todos, JÄGER, Siegfried, "Entre las culturas: caminos fronterizos en el análisis del discurso", Discurso y Sociedad, 2 (3), 2008, p.503-532.

${ }^{22}$ Por todos, YVONNE, Media \& Crime, cit. nota $n^{\circ} 8$, p.26.

${ }^{23}$ VAN DIJK, "El análisis", cit. nota n 2, pp. 31-32.
} 
Polít. crim. Vol. 8, № 16 (Diciembre 2013), Art. 4, pp. 472-499.

[http://www.politicacriminal.cl/Vol_08/n_16/Vol8N16A4.pdf]

red de discursos alternativos.

\subsection{El posmodernismo o modernismo tardío.}

El ACD, sin duda, posee varios puntos de conexión con el pensamiento posmodernista. ${ }^{24}$ No obstante, debe advertirse desde ya la necesidad de diferenciar entre el posmodernismo como corriente de pensamiento y el posmodernismo como fenómeno social, ya que en el primer caso, constituye un nuevo paradigma para comprender y, en su caso, intervenir en las relaciones sociales; y en el segundo caso, constituye un fenómeno social, objeto de estudio de varias disciplinas sociales realizado, en muchas ocasiones, a partir de postulados modernistas.

El pensamiento postmodernista ha tenido un significativo impacto en las ciencias sociales $\mathrm{y}$, especialmente, en la criminología. Así, debemos destacar en entre su principales característica su recelo hacia los conceptos de veracidad y falsedad y una cierta incredulidad hacia las metanarrativas. Las relaciones sociales son vistas como inherentemente caóticas y contingentes, más que en un sistema coherente que es regulado por principios universales como, por ejemplo, la lucha de clases. La sociedad se caracteriza por estar en un constante proceso de cambio. No existe una sola verdad sino numerosas verdades en un proceso constante de cambio. El único rasgo universal en las relaciones sociales es la manera en que los individuos buscan imponerse sobre otros.

En su forma más radical manifiesta una desconfianza hacia el conocimiento en su rol emancipatorio y, en su lugar, reivindica la naturaleza relativa del conocimiento tanto para el individuo como para grupos sociales. El posmodernismo manifiesta una oposición al «objetivismo» en el sentido de antirrealista. No obstante, gran parte de sus seguidores prefieren denominar este nuevo paradigma social como el «modernismo tardío», poniendo énfasis en el hecho de que en la actualidad, a pesar de los importantes cambios sociales y culturales, permanece intacta la estructura de la sociedad moderna: clases sociales, capitalismo, militarismo, nación, etc.

El posmodernismo como corriente de pensamiento, afirma que en todos los textos modernos llegó siempre un momento en el que los hechos empíricos se agotaron y las deducciones de principio alcanzaron un límite, o ambas situaciones a la vez. ${ }^{25}$ Antes estos límites se acuden a usos ilegítimos del razonamiento que sirven como cláusula de cierre de una determinada decisión presuntamente fundamentada que, en realidad, constituyen manifestaciones del puro subjetivismo (actos de fe, posiciones ideológicas, intereses personales o corporativos, etc.). ${ }^{26}$

\footnotetext{
${ }^{24}$ Véase en extenso un análisis crítico en: ALONSO, Luis Enrique y CALLEJO, Javier, "El análisis del discurso: del posmodernismo a las razones prácticas", Reus no 8 (1999), pp. 37-68.

${ }^{25}$ HARCOURT, Bernard, "Meditaciones postmodernas sobre el castigo: acerca de los límites de la razón y de las virtudes de aleatoriedad (una polémica y un manifiesto)", Revista de Derecho Penal y Criminología n 90 , Vol. XXXI (2010), p.18.

${ }^{26}$ Sin compartir los postulados más radicales del postmodernismo, he mantenido en un estudio relativo al denominado principio o juicio de proporcionalidad, que la concreción de cuándo una determinada injerencia en un derecho fundamental resulta especialmente grave o inaceptable queda a la mera arbitrariedad del juzgador. FERNÁNDEZ CRUZ, José Ángel, "El juicio constitucional de proporcionalidad de las leyes
} 
Ante esta situación el pensamiento posmodernista otorga un papel preponderante al discurso, incluso, las posiciones más radicales rechazan cualquier práctica social que no sea estrictamente lingüística. ${ }^{27}$ El lenguaje constituye un variable fundamental en las relaciones sociales y, en especial, en aquellas que participan instituciones públicas: la realidad social esta limitada y construida por la realidad colectiva del lenguaje. En otras palabras, no existe una necesaria conexión lógica entre el uso del lenguaje y lo que se pretende describir, no existen "verdades objetivas" sino diferentes maneras de describir las relaciones sociales. ${ }^{28}$ Como podemos apreciar, esta especie de cierre discursivo denota un antisociologismo latente o manifiesto ${ }^{29} \mathrm{y}$, en el caso que nos ocupa, un rechazo a la criminología tradicional fundamentada en datos empíricos.

En cuanto a la metodología postmoderna, debemos destacar las propuestas deconstructivistas. La deconstrucción radica en levantar las trampas de los textos que solo pueden apelar a otros textos como mecanismo de justificación y legitimación y que, en último término convierte a los discursos en la "única realidad". Critican la tradición occidental de creación de significados estables, afirmando que el conocimiento humano es producto contingente de prácticas lingüísticas plurisignificativas, que se resisten a ser encajadas en cualquier representación de la realidad externa que no sea otra narración particular, local y subjetiva. ${ }^{30}$ De esta forma, el deconstructivismo critica los sistemas de valores jerárquicos expresados en los textos, puesto que las verdades absolutas solo suponen el producto de un sistema de significación (a través de diferir las posibilidades del significado). La verdad que se plasma en los textos (modernos) se forma, por una parte, mediante una red lingüística de exclusiones y diferenciaciones latentes construidas a partir de posiciones discursivas y, por otra, a través de parasitar en otros textos que, en último término, no tienen ninguna conexión con la realidad objetiva. Harcourt manifiesta que las disciplinas que forman parte del campo del delito acuden a una fuerza interpretativa sustentada en la fe (fuerza performativa). El momento de establecer, por ejemplo, una condena justa y proporcionada, representa un enunciado violentamente performativo, un hecho que al ser expresado realiza el propio hecho, a saber, una interpretación que no es justa ni injusta ${ }^{31}$.

penales: ¿la legitimación democrática como medio para mitigar su inherente irracionalidad?”, Revista de Derecho Universidad Católica del Norte, Sección Estudios, Año 17- nº 1 (2010), pp. 51-99.

${ }^{27}$ Otras posiciones posmodernistas proponen otras cláusulas de cierre. Podemos destacar en el ámbito de la teoría de la pena, la propuesta de Harcourt que, tras establecer los límites de principio y criminológicos para determinar qué tipos de penas deben imponerse y en qué extensión, acude al parámetro de la aleatoriedad. HARCOURT, "Meditaciones postmodernas", cit. nota ${ }^{\circ} 25$, pp. 22-45. No obstante, el autor establece unos límites a la aleatoriedad: "Solo recurriremos al azar cuando nuestra ciencia social y nuestros principios se agotan". El autor citado aboga por una física social, es decir, no sujeta a la intermediación humana, poniendo, por ejemplo, la teoría de la incapacitación o inoculación que se concretaría mediante la aleatoriedad. En fin, estamos ante un ejemplo de cómo el posmodernismo puede derivar en el delirio, a pesar de que como manifiesta el autor, podamos encontrar ejemplos de medidas fundamentadas en la aleatoriedad. HARCOURT, "Meditaciones postmodernas", cit. nota n 25, pp.33-34. Así, podríamos mencionar, la menor penalidad de la tentativa respecto de la frustración que se justifica para algunos (finalismo ortodoxo) en la mera aleatoriedad.

28 ARRIGO, B. y BERNARD, T., "Posmodern Criminology in Relation to Radical and Conflict Criminology", Critical Criminology n 8 (1997), p. 39.

${ }^{29}$ ALONSO/CALLEJO, "El análisis del discurso", cit. nota n² 24, p. 40.

${ }^{30}$ ALONSO/CALLEJO, "El análisis del discurso", cit. nota n ${ }^{\circ} 24$, p. 58.

${ }^{31}$ HARCOURT, "Meditaciones postmodernas", cit. nota ${ }^{\circ}$ 25, p. 28. 
La influencia del deconstructivismo en el ACD se presenta en el denominado análisis intertextual, que consiste en la comprensión de un texto, no a través del análisis del contexto social, sino a través de la búsqueda de otros discursos desarrollados en otros textos.

No obstante, el ACD se aleja de las corrientes posmodernistas más radicales. Debemos recordar que una de las principales características del ACD radica, precisamente, en el análisis del contexto social e histórico. Tampoco asume los postulados antirrealistas del pensamiento deconstructivista. Como advierte Fairclough, el ACD debe evitar la tentación de reducir el poder exclusivamente al lenguaje. ${ }^{32}$ Como hemos manifestado, el ACD transciende a la espera interna del texto o del discurso y acude al conocimiento del trasfondo de las relaciones sociales, económicas y políticas. Es más, el ACD pretende ser un puente entre la observación y análisis de la desigualdad social y el estudio de la gramática, la semántica, los actos de habla, etc.

El posmodernismo ha tenido también su reflejo en la criminología. La criminología posmoderna entiende el delito en términos de producción lingüística y de relaciones de dominación, poniendo especial énfasis en el poder como una característica omnipresente en las relaciones sociales. Así, el delincuente es construido a través de los discursos dominantes y las relaciones de resistencia y poder. ${ }^{33}$ Postula que quien controla los significados de la expresión tienen la capacidad de ejercer el poder sobre otros.

La criminología posmoderna se centra en explorar los "micro-procesos de poder" que operan en instituciones como la policía, tribunales y prisiones. Simultáneamente, estos microprocesos de poder generan resistencia que resulta silenciada por los medios dominantes de expresión. Luego, para la criminología posmoderna el elemento fundamental de estudio en las relaciones sociales radica en el discurso y, en especial, en aquellas relaciones de poder y desigualdad social que son escondidas por los discursos dominantes.

El principal método utilizado por la criminología posmoderna es, precisamente, el análisis del discurso, es decir, la deconstrucción de los significados para revelar, por un parte, las relaciones de poder y, por otra, los discursos suprimidos. En sus análisis resulta de especial relevancia la posición que ocupa el sujeto en las relaciones discursivas. Así, en el campo de la política criminal existen varios roles o posiciones sociales (abogados, jueces, policías, etc.) que son asumidos en mayor o menor medida por los sujetos que forman parte de ellos. Así el discurso, por ejemplo, de un policía reflejará lo que se supone que debe ser un policía, es decir, asumirá la posición del discurso policial dominante. ${ }^{34}$

También puede apreciarse una influencia del posmodernismo -como nuevo paradigma social- en los fenómenos del miedo al delito y de la victimización. Estamos ante una manifestación de las audiencias como creadoras de significados. La idea de que todos podemos ser potenciales víctimas de un delito constituye una manifestación del

\footnotetext{
${ }^{32}$ FAIRCLOUGH, Norman, Language and power, Londres: Longman, 1989, p. 26.

${ }^{33}$ ARRIGO/BERNARD, "Posmodern Criminology", cit. nota $\mathrm{n}^{\circ} 28, \mathrm{p} .41$.

${ }^{34}$ ARRIGO/BERNARD, "Posmodern Criminology", cit. nota n 28, p, 48.
} 
FERNÁNDEZ, José Ángel. “Análisis crítico del discurso y criminología.

Una aproximación interdisciplinar"

posmodernismo. La criminología posmodernista rechaza la tradicional concepción de la etiología del crimen (causa-efecto), poniendo el énfasis en la fragmentación social, el miedo de las comunidades y la aleatoriedad de violencia que irrumpe en todas las capas de la sociedad. Este miedo acechante e impredecible es aumentado y, en ocasiones, generado por los medios de comunicación.

Relacionado con la anterior afirmación, el posmodernismo presta especial atención al proceso de desregularización y profusión de los medios de comunicación. Así, sus estudios de textos suelen centrarse más en el estilo y formato de la información que en su contenido. Por ejemplo, la información televisiva suele presentarse en periodos que no superan los tres minutos y, en muchas ocasiones, presentado en un formato de entretenimiento. De esta manera, el formato y estilo de los medios de comunicación han contribuido a una cultura de la inmediatez y del sensacionalismo, es decir, a una falta de profundidad en el análisis y contextualización de la noticia. En otras, palabras, el posmodernismo ha difuminado las diferencias entre entretenimiento e información. Así, la fragmentariedad, lo efímero, la ambigüedad, el placer, el espectáculo, la imitación, la parodia y la ironía son las características posmodernas de los medios de comunicación. La violencia forma parte de la cultura del entretenimiento y, a la vez, la audiencia es más insensible y despegada de la ingente cantidad de imágenes violentas con las que son bombardeadas diariamente. Este incremento de la violencia en los medios de comunicación ha sido explicado a través de la teoría de la aceleración, que consiste en la utilización de un discurso dramático como mecanismo para mantener la atención de la audiencia. Otra característica del entretenimiento posmodernista radica en la incapacidad o falta de voluntad por separar entre un hecho extraordinario y un hecho ordinario, como por ejemplo, el continuo bombardeo sobre la audiencia con crímenes poco comunes y atípicos.

La criminología posmoderna ha sido objeto de varias críticas. La más importante, quizá, la dirigida a una sus las principales premisas: el radical rechazo del proyecto de reforma fundamentado en la recolección y análisis de datos. Afirmación que también se ha trasladado a la criminología. Esta afirmación contrasta con el extraordinario avance en las técnicas de investigación empírica que se ha producido en los últimos decenios por lo que la defunción del fin del Proyecto Iluminista resulta, cuando menos, cuestionable. Más bien lo que ha puesto de manifiesto o ha recordado el pensamiento posmodernista es la existencia de algunos límites a la hora de observar y analizar la realidad criminal, teniendo presente que unos de ellos han surgido, precisamente, como consecuencia del avance en la metodología y técnicas de investigación de la criminología moderna. ${ }^{35}$

Resulta también especialmente relevante la crítica surgida en las propias filas de la criminología crítica o radical, en concreto, la realizada por el realismo de izquierdas o crítico, controversia que recuerda a la que tuvo lugar en los años 70 entre este último y el idealismo de izquierda. $^{36}$

\footnotetext{
${ }^{35}$ Véase, FERNÁNDEZ CRUZ, José Ángel, "Legitimación social de las leyes penales. Límites y ámbito de aplicación", Revista de Derecho Universidad Católica de Valparaíso. XXXIII (Valparaíso, Chile, $2^{\circ}$ Semestre de 2009), pp. $231-259$.

${ }^{36}$ LEA, John y YOUNG, Jock, ¿Qué hacer con la ley y el orden?, Buenos Aires: Ediciones del Puerto, 2001.
} 
Pavlich entiende que el realismo de izquierdas ha comprometido al pensamiento crítico, apelando a una reivindicación del conocimiento anacrónico y gerencial que, en último término, deriva en una forma de pragmatismo. Mantiene que la pretensión crítica del realismo criminológico por sí mismo resulta de imposible consecución y ha finalizado siendo parte de la agenda política conservadora, operando con un método modernista obsoleto. ${ }^{37}$ Mattews responde a esta crítica, manifestando que este derrotismo posmoderno resulta poco atractivo en la mayor parte de los asuntos sometidos a la agenda política. ${ }^{38} \mathrm{Sin}$ duda, si el crimen no fuese un problema serio, los medios de comunicación por sí solos no tendrían el poder de influencia sobre la audiencia. Sin embargo, aunque la criminología posmoderna presenta al Proyecto Iluminista como un espejismo, una parte de ella manifiesta que la ilusión modernista constituye la mejor forma de vida. ${ }^{39}$

Otra crítica radica en el supuesto proceso de superación o rechazo de las grandes metanarrativas. El posmodernismo, inevitablemente, construye su propia gran narrativa y conceptos contextualizados a esta, mientras gira hacia el relativismo e idealismo. ${ }^{40}$ Un ejemplo en esta situación es la crítica de Carol Smart sobre la criminología masculina que ha imperado en la modernidad. La criminología, en palabras de la autora, se ha centrado, desde todas las perspectivas, en la masculinidad, y ante esta situación aboga por su

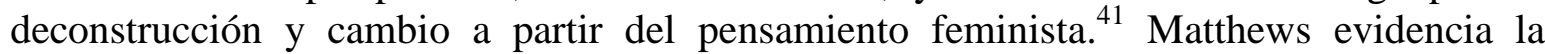
contradicción de esta propuesta: la deconstrucción de una ciencia criminológica que, desde una perspectiva masculina, ha pretendido ser universal, quiera superarla con otra visión parcial y reduccionista. La propuesta mantenida por Smart se encarga más de reprochar el pasado que de construir las bases de para el desarrollo de una criminología feminista. ${ }^{42}$ Esta propuesta feminista constituye una visión antimodernista y antirrealistas de la criminología que deriva en el relativismo y el fundamentalismo (bienestarismo autoritario). Como ha señalado John Lee, el cambio de una corriente del pensamiento dominante por la sustentada en la marginalización, victimización y exclusión de las mujeres, significa reemplazar una forma de fundamentalismo por otra. ${ }^{43}$

\subsection{Los estudios culturales.}

El ACD encuentra numerosos puntos de conexión con los denominados estudios culturales, que contienen, a la vez, una clara influencia del pensamiento posmoderno. Aquí la cultura no es el producto estético o artístico del espíritu humano, sino el modo de vivir en la

\footnotetext{
37 PAVLICH, George, "Criticism and criminology: in search of legitimacy", Theoretical Criminology $\mathrm{n}^{\circ} 3$ (1999), pp.29-53.

${ }^{38}$ MATTHEWS, Roger A., “The construction of 'So What?' criminology: a realist analysis”, Crime, Law and Social Change 54 (2010), p. 126.

${ }^{39}$ WHITE, Rob y HAINES, Fiona, Crime and Criminology. An introduction, $3^{\mathrm{a}}$ ed., Oxford Univesity Press, 2004, pp.206-209.

${ }^{40}$ MATTHEWS, “The construction”, cit. nota ${ }^{\circ}$ 38, p. 126.

41 SMART, Carol, "Feminist approaches to criminology or postmodern woman meets atavistic man", en: MORRIS, A. \& GELSTHOPE L. (Eds.), Feminist perspectives in criminology, Milton Keynes: Open University Press, 1990.

${ }^{42}$ MATTHEWS, "The construction", cit. nota ${ }^{\circ}$ 38, p. 127.

${ }^{43}$ LEA, J., "Criminology and postmodernity", en: WALTON \& YOUNG J. (Eds.) The new criminology revisited, London: Macmillan, 1998, p. 89.
} 
FERNÁNDEZ, José Ángel. “Análisis crítico del discurso y criminología.

Una aproximación interdisciplinar"

sociedad industrial, que incluye la experiencia social y, en especial, la construcción de identidades sociales. Comparte con el ACD la convicción de que la realidad solo puede ser dotada de sentido a través del lenguaje. Por esta razón, prestan especial atención a las instituciones que generan los principales discursos sociales como la escuela, la familia, los medios de comunicación, etc.

Althusser, desde una concepción de la ideología dominante, designa a las anteriores instituciones como los aparatos ideológicos del estado, que tienen como función persuadir a los individuos de la clase dominada para que se comporten socialmente de una manera aceptable. $^{44}$ En cambio, otros estudios culturales entienden que los textos y, en especial, los programas televisivos no tienen un significado único y lineal, sino que son relativamente abiertos. Esto permite una cierta negociación entre la situación personal con los significados que pueden derivarse del texto. Así, Stuart Hall, el precursor de esta corriente, mantiene que, por ejemplo, los programas de televisión contienen un conjunto de significados relacionados con las ideologías dominantes, que conviven con otros significados y que a la vez pueden ser percibidos por los lectores (televidentes). Normalmente esta relación no será de confrontación sino negociada, es decir, el propio lector de acuerdo con su experiencia e ideología da un determinado sentido al texto. De esta manera, los medios de comunicación en general con el fin de captar una mayor audiencia incluyen una escala de lecturas negociadas a través de los cuales los diferentes grupos sociales pueden encontrar significantes relacionados con la ideología dominante. A partir de aquí, se ha desarrollado una rama etnográfica de los estudios culturales que se centra en la investigación de la heterogeneidad de las audiencias.

Encontramos, también, una rama discursiva de los estudios culturales. Morley, a partir de la teoría de Stuart Hall -aunque critica que las diferentes lecturas de un texto sean definidas, principalmente, por la clase social- desarrolla una teoría del discurso. Entiende que existe una amplia gama de lecturas de un determinado evento o hecho. La conciencia de los lectores está construida por un número de discursos a través de los cuales este da sentido a su experiencia social. Así cuando un lector se enfrenta a un texto, por ejemplo, a un texto televisivo, se produce una negociación entre los discursos del lector previamente construidos y los discursos ofrecidos por el nuevo texto. ${ }^{45}$ Esta corriente discursiva cambia el paradigma de los estudios culturales de los años 70: los textos ya no pueden ser vistos como una entidad autosuficiente, que ejerce una misma influencia o control, sino que, por el contrario, generan numerosos discursos a través de los procesos cognitivos de los participantes. En esta teoría del discurso las clases dominantes ejercen su control delimitando dentro de los textos el terreno dentro del cual la variedad de lecturas pueden ser negociadas. ${ }^{46}$

\footnotetext{
${ }^{44}$ FISKE, "Los estudios culturales", cit. nota no 18 , p. 2.

${ }^{45}$ Van Dijk critica la posición de Morley sobre la negociación con discursos previos leídos/escuchados por los receptores. La psicología del discurso mantiene que la memoria de los discursos es mínimo y por lo tanto la experiencia social per se aporta poco a este negociación. Lo que se memoriza son los modelos mentales y representaciones construidas durante la lectura de los discursos previos. VAN DIJK, Teun, Comentarios a este estudio.

${ }^{46}$ FISKE, "Los estudios culturales", cit. nota n ${ }^{\circ} 18$, pp. 6-7.
} 
En el ámbito del ACD se ha producido en los últimos tiempos una convergencia con el paradigma cultural. Así cabe destacar, al propio Fairclough que ha realizado un estudio crítico de los medios de comunicación bajo esta teoría o paradigma. ${ }^{47}$ Como hemos mencionado, los estudios culturales otorgan a los discursos un papel esencial a la hora de configurar una determinada cultura. Jäger, tomando como referencia al científico cultural Gerhard Neumann, entiende que la cultura no es otra cosa que el contexto: "los cuerpos y lenguajes que proporcionan los signos que circulan por dicho contexto. En esencia, la cultura tiene un carácter semiótico". ${ }^{4}$

Los estudios culturales han tenido su reflejo en la criminología. La criminológica cultural toma como objeto de estudio el imperativo posmoderno del entretenimiento. Parte del presupuesto de que todo crimen encuentra su explicación en las prácticas culturales y que estas forman parte de los procesos de dominación. Pero a diferencia de parte de la criminología crítica (marxista), entienden el crimen, no como una resistencia a la autoridad, sino como la internalización o expresión de una subcultura. Así, ponen especial atención en la seducción, fascinación e, incluso, éxtasis que produce el crimen y su tratamiento como espectáculo.

Muchos crímenes, de acuerdo con la criminología cultural, representan la intención de tomar el control y ejercer la responsabilidad del propio destino: en un mundo donde los individuos se encuentran dirigidos por las instituciones sociales y culturales, el crimen permite recuperar el propio control de sus actos. Puesto que la criminología cultural entiende el crimen o, al menos, parte de la criminalidad, como una representación teatral, gran parte de sus investigaciones se han centrado en fenómenos sociales como las revueltas, disturbios, etc.

\subsection{Las teorías socio-cognitivas del contexto.}

Como veremos con posterioridad, una de las principales características del ADC radica en la incorporación de las ciencias sociales, asociación que permite determinar el contexto social donde se producen los eventos discursivos. Los procesos discursivos solo pueden entenderse en relación a un determinado contexto, es decir, se encuentran constreñidos por una serie de condicionamientos sociales. ${ }^{49}$ Por tanto, el ACD necesita de una teoría del contexto que permita comprender y analizar cómo se relacionan estos condicionamientos con la producción y recepción de los discursos. Mencionaremos someramente la propuesta sociocognitiva desarrollada por Van Dijk, uno de los analistas del discurso que ha prestado mayor atención en la teoría del contexto.

Para esta teoría los contextos poseen una clara naturaleza cognitiva, pertenecen a la

\footnotetext{
47 FAIRCLOUGH, Norman, "Políticamente correcto: la política de la lengua y la cultura", Sociedad y Discurso, GHIO, Elsa, (trad.), Vol. 3(3), 2009, pp. 495- 512.

48 NEUMANN, Gerhard, "Die Zirkulation der sozialen Energie abbilden. Literaturwissenschaft als Kulturwissenschaft: die konfligierenden Bedeutungsmuster von Literatur und Lebenswelt", en Frankfurter Rundschau, 1995. Citado, JÄGER, "Entre culturas”, cit. nota n² 21, p. 508.

49 Por todos, MEYER, Michael, "Entre la teoría, el método y la política: la ubicación de los enfoques relacionados con el ACD”, en: WODAK/MEYER (Comps.), Métodos de análisis crítico del discurso, p. 37.
} 
FERNÁNDEZ, José Ángel. "Análisis crítico del discurso y criminología.

Una aproximación interdisciplinar"

categoría más amplia de modelo mental desarrollado por la psicología. ${ }^{50}$ Esto significa que se aparta de las propuestas deterministas y conductistas, es decir, rechaza que la existencia de los hechos o situaciones sociales, como la raza, la clase social o el género influyan de manera directa en el modo en el que hablamos o escribimos. Por el contrario, la teoría sociocognitiva entiende que las propiedades sociales se encuentran mediatizadas por la biografía de los participantes del discurso a la hora de producir o interpretar los textos. Para esta teoría el contexto discursivo tiene, por tanto, una clara naturaleza subjetiva. La situación social objetiva no afecta al discurso sino a su representación por parte de los participantes. En sentido contrario, la influencia directa de las situaciones sociales en el discurso, conllevaría a que todos los participantes en la misma situación social hablarían de la misma manera, lo que obviamente no es así. ${ }^{51}$ Así, la teoría sociocognitiva del contexto analiza cómo los participantes del discurso se representan en las situaciones sociales y cómo estas representaciones sociales influyen en la comprensión y producción del discurso. Constituye el eslabón perdido entre las estructuras sociales y el discurso.

Cuando el modelo mental se refiere a una situación o hecho comunicativo, el modelo mental se denomina, como hemos mencionado, contexto. Los contextos son construcciones mentales (modelos), porque representan lo que los usuarios del lenguaje entienden como relevante en la situación social a la hora de producir o recibir un discurso. ${ }^{52}$ Estos contextos no solo comprenden representaciones individuales, sino también representaciones que son compartidas por el grupo, como el conocimiento, las actitudes y la ideología. ${ }^{53}$ Por tanto, los modelos contextuales constituyen per se una forma de controlar la mente.

Una distinción (cognitiva) utilizada por los analistas críticos del discurso es la que diferencia entre la memoria personal o subjetiva y la social o intersubjetiva. La primera representa nuestras vivencias y opiniones personales sobre hechos y discursos donde hemos participado. Estas representaciones memorísticas también incluyen representaciones sobre la propia situación comunicativa, por ejemplo, el conocimiento y opinión de un medio de comunicación o de un determinado experto. La memoria social contiene las creencias que poseemos en común, denominadas representaciones sociales. Normalmente, una representación social es general y abstracta, aunque puede referirse a hechos históricos concretos como, por ejemplo, la comisión de un delito de gran connotación social. Se suele distinguir entre conocimiento social -creencias compartidas que se consideran verdaderasy opiniones sociales -creencias evaluativas que están fundamentadas en normas y valores que son compartidos socialmente-. Las primeras, no necesitan de justificación alguna, mientras que las segundas, se afirman y defienden. Por supuesto, la memoria subjetiva e intersubjetiva se complementan: no podemos crear un modelo mental sin previamente poseer un propio conocimiento y opinión general. En este sentido, los modelos mentales o contextos, debido a la similitud de las vivencias personales y a la influencia de las representaciones sociales compartidas, tienden a ser bastantes similares. ${ }^{54}$

\footnotetext{
${ }^{50}$ Véase los autores citados por VAN DIJK, Sociedad y Discurso, cit. nota $\mathrm{n}^{\circ} 13$, p. 21.

${ }^{51}$ VAN DIJK, Sociedad y Discurso, cit. nota ${ }^{\circ} 13$, p. 21.

${ }^{52}$ VAN DIJK, "El análisis", cit. nota n 2, p. 26.

${ }^{53}$ VAN DIJK, "El análisis", cit. nota n², p. 27.

${ }^{54}$ VAN DIJK, Teun, “Algunos principios de una teoría del contexto", Revista latinoamericana de estudios del discurso, núm. 1 (2001), p.72.
} 
Al ACD le interesa en especial cómo el discurso influye en las creencias compartidas o representaciones sociales, ya que consideran que constituyen los principales medios de dominación social. Como manifiesta Jäger, la cohesión de los discursos se produce o se ve garantizada por sistemas de simbolismo colectivo. ${ }^{55}$

Los modelos de contexto tienen una naturaleza dinámica, cambian constantemente, incluso, durante el propio evento comunicativo. No obstante, Van Dijk entiende que los contextos poseen unas estructuras, más o menos, fijas entre las que podemos destacar: (1) El dominio general que representa el ámbito general donde se desarrolla el discurso, por ejemplo, la educación o, en nuestro caso, la criminalidad. (2) El tipo de participante y su papel comunicativo como el hablante/oyente, hombre/ mujer, etc. Respecto a este último, debemos destacar la concurrencia de los denominados participantes globales (nosotros y ellos) que son utilizados para representar los discursos colectivos o representaciones sociales. (3) Y la cognición que representa los conocimientos, opiniones y objetivos que poseen los interlocutores. Resulta relevante para la creación y procesamiento de un discurso los conocimientos, opiniones y objetivos de los interlocutores, el nivel detalle del discurso, etc. ${ }^{56}$ Por tanto, los contextos controlan que la producción y recepción del discurso a la hora de manifestarse sea adecuada a la situación interpersonal y social de cada participante.

Algunas estructuras discursivas son más propicias a verse influenciadas por el contexto (sensitive context) como, por ejemplo, el léxico, el orden las palabras, los tiempos verbales, etc. También existen varios factores o situaciones que favorecen la creación de representaciones sociales $y$, por ende, un mayor control de la mente. Van Dijk nos proporciona algunos ejemplos: ${ }^{57}$

a) Los receptores tienden a aceptar los conocimientos y opiniones trasmitidos por las fuentes que consideran autorizadas o fidedignas. Por tanto, estos discursos per se constituyen un elemento de poder.

b) En algunas ocasiones los participantes están obligados a ser receptores del discurso, por ejemplo, los alumnos en las aulas de las facultades de derecho. Así, estos discursos forzosos necesitan de ser aprendidos o interpretados como lo presentan los autores.

c) En otros casos, no existen otros discursos que provean de opiniones alternativas. El tratamiento de los medios de comunicación sobre la criminalidad y los medios de control penal constituye un ejemplo paradigmático de esta situación.

d) También, resulta frecuente que los receptores no posean el conocimiento y creencias suficientes para desafiar a los discursos a los que se encuentran expuestos.

Esta teoría sociocognitiva del contexto posee evidentes similitudes con la larga tradición criminológica cognitiva. Basta con mencionar la teoría de Hirschi y Gottfredson que pone especial énfasis en la capacidad de autocontrol para explicar las conductas criminales, o la aplicación de modelos cognitivos para entender las conductas criminales y, en especial,

\footnotetext{
${ }^{55}$ Por todos, JÄGER, "Entre culturas", cit. nota n 21, p. 551.

${ }^{56}$ VAN DIJK, “Algunos principios”, cit. nota ${ }^{\circ}$ 54, pp. 77-79.

${ }^{57}$ VAN DIJK, “El análisis", cit. nota n 2, p. 29.
} 
FERNÁNDEZ, José Ángel. “Análisis crítico del discurso y criminología.

Una aproximación interdisciplinar"

cómo procesan y responde a la información procedente un determinado contexto social. ${ }^{58}$ La criminología cognitiva se ha centrado más en los actos criminales que en los discursos, ya que la mayoría de los delitos pueden ser percibidos por los sentidos. Pero como venimos afirmando en el presente estudio, la realidad discursiva resulta especialmente patente en el ámbito de la criminalidad y en los medios de control social. Por tanto, podríamos afirmar que la teoría sociocognitiva del contexto aplicada a la criminalidad y a los medios de control social intenta explicar cómo la biografía de los participantes (criminales, legisladores, policías) incide en la recepción y creación de un evento discursivo.

\section{El Análisis Crítico del Discurso: su dimensión criminológica y político criminal.}

Analizadas someramente el acervo común de la criminología y otras ciencias sociales que comparte con el ACD, pasamos abordar sus principales características relacionadas con las ciencias penales.

El ACD es un tipo de investigación analítica del discurso que estudia el modo en que el abuso del poder y la desigualdad social son practicados, reproducidos y, en menor medida, combatidos por los textos y el habla en un determinado contexto social y político. ${ }^{59}-{ }^{60} \mathrm{~A}$ partir de su propio título, podemos extraer sus principales notas características. El discurso es considerado como una práctica social que, a la vez y valga la redundancia, está configurado por el propio contexto social. ${ }^{61}$ El análisis radica en el estudio de las relaciones dialécticas entre la semiosis y otros elementos de las prácticas sociales. ${ }^{62}$ Y lo crítico nos indica que su ámbito de análisis se centra en las relaciones discursivas entre los que más sufren y los que detentan el poder. Se preocupa, por tanto, de las relaciones entre lenguaje y poder. ${ }^{63}$ Por esta razón, sus análisis se centran en los discursos institucionales, políticos, de género y mediáticos que dan testimonio de la existencia de relaciones de dominación y conflicto. $^{64}$

Como manifiesta Van Dijk:

\footnotetext{
${ }^{58}$ Véase una explicación general de los modelos cognitivos en el ámbito de la etiología y el tratamiento penitenciario en: HOLLIN, Clive R., "Criminological psychology" en: MAGUIRE et alii, (Eds.), The Oxford Handbook of Criminology, Oxford: Oxford University Press, $4^{\mathrm{a}}$ ed., 2007, pp. 57-63.

${ }^{59}$ VAN DIJK, "El análisis", cit. nota n ${ }^{\circ} 2$, p.23.

${ }^{60} \mathrm{Su}$ orientación crítica hacia el lenguaje y el discurso se inició con la "lingüística crítica" nacida, principalmente, en el Reino Unido y Australia hacia finales de los años setenta por autores como Fowler, Hodge, Kress y Trew, y Mey. VAN DIJK, "El análisis", cit. nota nº 2, p. 23.

${ }^{61}$ FAIRCLOUGH, Norman, "El análisis crítico del discurso como método de investigación de las ciencias sociales", en: WODAK, Ruth; MEYER, Michael (Comps.), Métodos de análisis crítico del discurso, Barcelona: Gedisa, (2003), p. 172.

${ }^{62}$ FAIRCLOUGH, "El análisis crítico del discurso como método", cit. nota n 61, p. 179.

${ }^{63}$ WODAK, Ruth, "De qué trata el análisis crítico del discurso (ACD) - Resumen de su historia, sus conceptos fundamentales y sus desarrollos" en: WODAK/MEYER (Comps.), Métodos de análisis crítico del discurso, cit. nota $\mathrm{n}^{\circ} 49$, p. 30 .

${ }^{64}$ WODAK, "De qué trata el análisis", cit. nota nº 63, p. 18.
} 
"Muchas tendencias en el análisis del discurso o de la conversación son teóricas o descriptivas, pero resultan escasamente explicativas. La perspectiva del ACD requiere una aproximación "funcional" que vaya más allá de los límites de la frase, y más allá de la acción y de la interacción, que intente explicar el uso del lenguaje y del discurso también en los términos más extensos de estructuras, procesos y constreñimientos sociales, políticos, culturales e históricos". 65

El ACD pretende hacer visible las estructuras lingüísticas de poder que aparecen en los textos, como de otras formas de creación de significado (imágenes, lenguaje corporal, etc.). ${ }^{66}$ El poder no solo influye en los procesos donde los discursos se trasforman en acciones, sino también en la creación de otros discursos. ${ }^{67}$ Además, existe un poder sobre el acceso a las formas de producción discursiva o, en otras palabras, el control de los medios donde se reproducen los discursos (medios de comunicación, universidades, centros religiosos, etc.) constituye un presupuesto necesario en la relaciones de dominación.

Como ciencia o saber social, además de su función descriptiva (criminología), posee una vocación de guía de la acción humana (político-criminal). Desde su perspectiva crítica entiende el discurso como un mecanismo de ilustración y emancipación. Para el ACD el lenguaje carece de poder propio y se obtiene por el uso que las personas hacen de él.

Propugna, en primer lugar, el desmantelamiento de aquellos discursos actualmente dominantes que actúan exacerbando los conflictos ligados a los otros (inmigrantes, criminales, etc.); y en segundo lugar, aboga por el desarrollo de una red de discursos alternativos, principalmente, en la política y los medios de comunicación que anule o mitigue estas relaciones de dominación, como por ejemplo, las guías destinadas a evitar la utilización de un lenguaje sexista. ${ }^{68}$ Por tanto, en su dimensión prescriptiva resulta perfectamente compatible con las propuestas ética-deliberativas o procedimentales. El discurso constituye -además de la existencia de unas más o menos abiertas relaciones de dominación y conflicto- la pretensión de imponer con buenas razones una determinada política criminal. En último término, el ACD pretende también la consecución de una situación ideal del habla. ${ }^{69}$

En conclusión, podemos apreciar con cierta facilidad que el ACD en el ámbito de la criminalidad y el Ius puniendi posee una dimensión, tanto criminológica, como político

\footnotetext{
${ }^{65}$ VAN DIJK, Teun A, "La multidisciplinariedad del análisis crítico del discurso: un alegato en favor de la diversidad”, en: WODAK/MEYER (Comps.), Métodos de análisis crítico del discurso, cit. nota n 49, p.174.

${ }^{66}$ WODAK, "De qué trata el análisis", cit. nota n 63 p. 20.

${ }^{67}$ Por todos, JÄGER, "Entre culturas", cit. nota n 21 , p.507.

68 JÄGER, "Entre culturas", cit. nota no 21, p.522. En el ámbito legislativo podemos encontrar medidas preventivas que inciden en la configuración de los discursos. Así, en el derecho español el Capítulo II de la Ley Orgánica 1/2004, de 28 de diciembre, de Medidas de Protección Integral contra la Violencia de Género establece varias medidas, como por ejemplo, la inclusión de un discurso que garantice la igualdad entre hombre y mujeres "desde la perspectiva de género", así como la formación discursiva de los profesionales de los medios de comunicación.

${ }^{69}$ Véase en extenso la aplicación de los postulados de la ética discursiva al derecho penal en: FERNÁNDEZ CRUZ, José Ángel, "La legitimación ética de las leyes penales. Reflexiones desde la ética procedimental”, Revista de Derecho (Valdivia), Vol. XXII-N 2, (Diciembre, 2009).
} 
FERNÁNDEZ, José Ángel. “Análisis crítico del discurso y criminología.

Una aproximación interdisciplinar"

criminal.

\subsection{EI ACD como una nueva perspectiva dentro de la Criminología crítica.}

El ACD, a pesar de autodefinirse como un saber con valores determinados y, por tanto, alejado del positivismo, proporciona detallados y sistemáticos análisis de las estructuras del texto y el habla y de sus relaciones con los contextos sociales y políticos. Es decir, sus conclusiones vienen avaladas por estudios concretos sobre textos $\mathrm{u}$ otras formas de reproducción externa del pensamiento, que intentan desentrañar las relaciones de poder y lucha manifestadas en los discursos. Y aquí reside, a mi modesto entender, la necesidad de incluir el ACD como una perspectiva más dentro de la criminología, al menos, la de corte crítica. La recogida de datos y la refutación de hipótesis criminológicas, que por sí se encuentran ya mediatizadas por el discurso (científico), resultan insuficientes para explicar la realidad social.

El ACD ofrece un análisis descriptivo de la realidad discursiva. Así, por ejemplo, el análisis de los discursos realizados en el seno de las organizaciones criminales en el ámbito de la etiología del crimen o el análisis de los debates parlamentarios respecto de los medios de control social puedan arrojar una información adicional o matizar la ya recogida por la criminología fáctica.

En consecuencia, y desde una perspectiva crítica, la observación y análisis de la desigualdad social es un ejercicio propio de las ciencias sociales (la criminología fundamentada en hechos), y el estudio de la gramática, la semántica, los actos de habla es una tarea general que corresponde a los lingüistas, así como a los analistas del discurso y de la conversación. ${ }^{70}$

A mayor abundamiento, el ACD no debe considerarse como una nueva corriente criminológica, en el sentido de que tenga que competir con otras escuelas o corrientes, sino una perspectiva complementaria (la discursiva) a la criminología crítica. ${ }^{71}$

\subsection{El carácter interdisciplinar del ACD: las aportaciones de la criminología.}

Si bien la mayoría de los estudios del ACD proceden del ámbito de la lingüística y la semiótica, sus principales exponentes no dudan en afirmar que, como consecuencia de las complejas relaciones entre lenguaje y sociedad, resulta preciso proceder a una investigación interdisciplinar. $^{72}$ El uso los discursos posee dimensiones intrínsecamente cognitivas, emocionales, sociales, políticas, culturales e históricas. Su teorización y análisis necesita,

\footnotetext{
${ }^{70}$ FAIRCLOUGH, "El análisis crítico del discurso como método”, cit. nota no 61, p.175.

${ }^{71}$ No obstante, como veremos a continuación, la denominada criminología posmoderna, la cual tiene como principal método de estudio el análisis del discurso, ha tratado de convertirse en un nuevo paradigma criminológico y lo que resulta más grave ha rechazado los métodos de investigación de la criminología moderna.

${ }^{72}$ MEYER, "Entre la teoría, el método", cit. nota n 49, pp. 38 y ss. Por su parte, Van Dijk no duda en afirmar que el "ACD puede combinarse con cualquier enfoque y subdisciplina de las humanidades y las ciencias sociales.”. VAN DIJK, "La multidisciplinariedad”, cit. nota n 65, p. 144.
} 
por ende, insertarse con el mayor número de teorías y metodologías desarrolladas por otras disciplinas. $^{73}$

Por tanto, el ACD pretende ofrecer análisis detallados y sistemáticos de las estructuras del texto y el habla y sus relaciones con los contextos sociales y políticos. ${ }^{74}$ Así, incluye dos tipos de análisis:

$1^{\circ}$ ) El análisis de los propios textos, que tiene como objetivo el descubrimiento de incoherencias, contradicciones, paradojas etc., (la "crítica inmanente del discurso").

$2^{\circ}$ ) El análisis del contexto social y histórico que tiene como propósito desmitificar el carácter manipulador de un determinado discurso (la "crítica sociodiagnóstica"). En esta fase se transciende la espera interna del texto o del discurso y se acude al conocimiento del trasfondo y del contexto de las relaciones sociales, económicas y políticas. ${ }^{75}$

Ahora bien, el término contexto profusamente utilizado por las ciencias sociales, resulta vago y ambiguo, por lo que resulta necesario delimitar su contenido y alcance. Esto quiere decir que se requiere una previa selección. Así, el contexto es entendido como aquellas propiedades de la situación comunicativa que resultan relevantes para el discurso. ${ }^{76}$

A partir de este análisis multidisciplinar nos permite establecer la denominada "práctica discursiva", es decir, la conexión entre el texto y la práctica social. Manifiesta, por una parte, cómo los participantes producen e interpretan los textos a partir de unos determinados contextos sociales, económicos e históricos; y por otra, cómo estos contextos limitan la propia práctica discursiva. ${ }^{77}$

El análisis de los textos junto a sus contextos sociales permite responder a las tres cuestiones básicas dentro del pensamiento crítico: (1) ¿Cómo los grupos más poderosos controlan el discurso?;(2) ¿Cómo este discurso controla la mente, la acción y el propio discurso de los grupos menos poderosos?; (3) y ¿cuáles son las consecuencias sociales de este control? ${ }^{78}$

Por, tanto, el carácter multidisciplinar del ACD llevado al terreno de la criminalidad significa que la criminología constituye una fuente de primer orden para conocer el contexto social asociado a un determinado discurso.

En sus estudios se suelen utilizar una serie de términos o conceptos claves relacionados con

\footnotetext{
${ }^{73}$ VAN DIJK, "El análisis", cit. nota ${ }^{\circ} 2$, p. 24.

${ }^{74}$ VAN DIJK, "El análisis", cit. nota n 2, p. 24.

75 WODAK, "De qué trata el análisis", cit. nota no 63, p. 103. El autor incluye una tercera crítica, la de "carácter pronosticador" destinada a transformar y mejorar la comunicación, que, como hemos mencionado, constituye la dimensión política criminal.

${ }^{76}$ VAN DIJK, Sociedad y discurso, cit. nota ${ }^{\circ} 13$, pp. 34-38.

77 Así, Fairclough desde su concepción marxista proclama que las prácticas discursivas se encuentran limitadas por el estado de las relaciones hegemónicas y las luchas por la hegemonía. FAIRCLOUGH, "El análisis crítico del discurso como método", cit. nota $\mathrm{n}^{\circ} 61, \mathrm{p} .176$.

${ }^{78}$ VAN DIJK, "El análisis", cit. nota n² 2, p. 26.
} 
FERNÁNDEZ, José Ángel. “Análisis crítico del discurso y criminología.

Una aproximación interdisciplinar"

el contexto social, entre los que podemos destacar los siguientes.

- Discurso en sentido abstracto: la concepción del uso lingüístico como una práctica social.

- Evento discursivo: cualquier creación concreta de significado. Constituye el principal objeto de estudio del ACD.

- Los discursos (en sentido específico): modo de significar la experiencia desde una perspectiva particular, como por ejemplo, el género, la inmigración, la educación, etc.

- Género: uso lingüístico asociado con una actividad social particular, como, por ejemplo, los artículos periodísticos.

- La interdiscursividad: la constitución de un texto a partir de diversos discursos. Por ejemplo, el Mensaje Presidencial sobre la Ley 20.000 sobre drogas recurre a varios discursos legitimantes, entre los que podemos destacar: el discurso de las organizaciones criminales, cuando la inmensa mayoría de los condenados por tráfico de drogas en Chile son pequeños traficantes; el discurso discriminatorio entre drogas legales o ilegales, cuando el consumo de alcohol en Chile es, sin duda, la droga que genera mayores daños sociales.

\subsection{El análisis de las estructuras discursivas.}

Como hemos mencionado, el ACD recurre a dos tipos de análisis: uno destinado al propio contexto social donde se produce el evento discursivo y otro respecto de las propias estructuras discursivas que aparecen el texto u otra formas de creación de significado. Continuando con la finalidad de este estudio, nos vamos a detener en el análisis de las estructuras discursivas que, desde la perspectiva criminológica, constituyen estudios de campo sobre la realidad discursiva. Así, mencionaremos algunas características generales, tipos de estructuras que tienen una especial capacidad para influir en de los participantes del discursos.

El ACD presta especial atención a aquellas estructuras del texto o de la conversación que están sujetas a cierto control de los participantes, como la entonación, las estructuras sintácticas, las figuras retóricas etc. Junto con el estudio de las categorías lingüísticas y sintácticas, el ACD analiza las formas de significados implícitos o indirectos, como las alusiones y las ambigüedades. Si bien los principales objetos de estudio son los textos escritos, incluyen asimismo la interacción conversacional, los gestos asociados, la mímica, las imágenes y cualquier otra dimensión "semiótica" o multimedia del significado. ${ }^{79} \mathrm{Un}$ aspecto esencial que debemos destacar es el análisis de los denominados "esquemas discursivos", que ponen de relieve cómo la sistematización o categorización de un texto puede subrayar o enfatizar una determinada información. Así, estos esquemas discursivos resultan esenciales en la desarrollo y profusión de las propuestas dogmático penales.

En cuanto al análisis de las categorías lingüísticas y sintácticas, los estudiosos del ACD se centran, como hemos mencionado, en el actor del discurso, prestando especial atención al uso de los pronombres, atributos, así como los tiempos verbales. ${ }^{80}$ Así, por ejemplo,

\footnotetext{
${ }^{79}$ MEYER, "Entre la teoría, el método", cit. nota no 49, p. 44.

${ }^{80}$ Por todos, MEYER, "Entre la teoría, el método", cit. nota ${ }^{\circ} 49$, p. 37.
} 
podemos destacar:

a) El uso de los pronombres personales. Por ejemplo, "nosotros" no solo establece un sentido de identidad entre el autor del discurso y los receptores, ${ }^{81}$ sino que también refuerza los valores y representaciones sociales entre los hablantes y otros miembros del endogrupo. El caso paradigmático lo encontramos en los discursos ideológicos. ${ }^{82}$

b) La utilización de las construcciones pasivas que se caracterizan por la ocultación del sujeto, ${ }^{83}$ en nuestro caso, por ejemplo, en el tratamiento informativo de la delincuencia de los poderosos.

b) La utilización de la sintaxis paratáctica. Este tipo de sintaxis se caracteriza por ordenar las oraciones como listas, en las cuales todas son equivalentes e iguales, al contrario de las relaciones de subordinación, donde una oración depende de la otra. En general, la parataxis es menos compleja que la hipotaxis (subordinación) y, a la vez, se presta a una mayor viveza expresiva. Se orienta más a plasmar evidencias que a ofrecer explicaciones, eludiendo de esta manera la cuestión de la agencia y las causas. En otras ocasiones, representa una manera de plasmar de forma asertiva la autoridad. ${ }^{84}$

Otros aspectos analizados son el tipo y forma de argumentación; el uso de metáforas, hipérboles, figuras retóricas, giros, refranes, tópicos; el énfasis y la entonación; la coherencia, el orden de las palabras etc. ${ }^{85}$

\section{Críticas al Análisis Crítico del Discurso.}

Varias han sido las críticas que ha recibido el ACD. Algunas ya han sido esbozadas en el anterior apartado como, por ejemplo, aquellas posiciones que otorgan al discurso un papel monopolístico o sobredimensionado.

Debemos destacar, en primer lugar, la vaguedad del término discurso que tiene tanto de vago como vocablo de moda. Resulta frecuente encontrar en las ciencias penales alusiones al término discurso, vacías de contenido, que sirven para explicar todos los males que acechan al poder punitivo, sin realizar una mínima aproximación científica. No obstante, como pone de manifiesto Van Dijk, la noción de discurso no es vaga, sino muy general, como lengua, sociedad, cognición o poder. ACD no estudia el discurso porque es la moda, sino porque es su objeto de estudio. Es igual de erróneo decir que la lingüística estudia la lengua o el lenguaje porque es la moda en otras disciplinas. ${ }^{86}$

En segundo lugar, el papel activo de los estudiosos del ACD puede en ocasiones traspasar

\footnotetext{
${ }^{81}$ TUPPER, Kenneth, "Drugs, discourses and education: a critical discourse analysis of high school drug education text", Discourse: Studies in the Cultural Politics of Education, vol.29, n 2 (2008), p. 227.

${ }^{82}$ VAN DIJK, Comentarios a este estudio (inédito).

${ }^{83}$ VAN DIJK, "La multidisciplinariedad", cit. nota n ${ }^{\circ} 63$, p. 59.

${ }^{84}$ También, la sintaxis paratáctica predomina en los procesos de cambio social. FAIRCLOUGH, Norman, "Representaciones del cambio en el discurso neoliberal", Cuadernos de Relaciones Laborales $\mathrm{n}^{\circ} 16$ (2000), pp. 27-28.

${ }^{85}$ MEYER, "Entre la teoría, el método", cit. nota no 49, p. 51.

${ }^{86}$ VAN DIJK, Comentarios y críticas a este estudio (inédito).
} 
FERNÁNDEZ, José Ángel. “Análisis crítico del discurso y criminología.

Una aproximación interdisciplinar"

la línea entre la investigación científica y la participación política, situación que puede derivar en una interpretación sesgada desde dos sentidos: el primero, porque el análisis se realiza a partir de algún tipo de compromiso ideológico y, por tanto, prejuicioso; y el segundo, porque el analista puede seleccionar, a priori, textos que se encuadran dentro sus preferencias científicas, sociales o ideológicas. ${ }^{87}$

\section{Como manifiesta Meyer:}

"En realidad, estas controversias son la concreción de dos posturas irreconciliables en el seno de la investigación social: ¿es posible efectuar cualquier tipo de investigación sin estar ligado, a priori, a ningún juicio de valor? y ¿es posible obtener conocimiento a partir de los datos puramente empíricos sin utilizar ninguna categoría o experiencia preconcebida? ${ }^{88}$ Por lo que respecta a la segunda pregunta, el ACD coincide incluso con la metodología positivista, que permite juicios de valor en el proceso de selección de objetos y en las preguntas que habrán de investigarse, ("contexto del descubrimiento"), pero los prohíbe en el "contexto de la justificación". En cuanto a la primera pregunta, la postura del ACD encaja bien con la mayor parte de la epistemología de tradición kantiana que niega la posibilidad del conocimiento puro". 89

A mayor abundamiento, el ACD, a diferencia de otros saberes, no niega sino que explícitamente define y defiende su propia posición sociopolítica. Incluso, y en palabras de Van Dijk, el ACD expresa un sesgo y está orgulloso de ello. ${ }^{90}$

En tercer lugar, el ACD puede ser criticado a su vez porque trasluce una concepción hobbesiana de la democracia. Respecto de su dimensión descriptiva, tras manifestar la visión sesgada del discurso capitalista destinado a legitimar y garantizar el poder establecido, no ofrece una explicación de por qué las minorías de hecho son protegidas por la dictatura de la mayoría democrática. En cuanto, a su dimensión prescriptiva, su vocación emancipadora puede generar manifestaciones del denominado bienestarismo autoritario. Así, por ejemplo, sería interesante un análisis crítico del discurso que estudiara de qué manera el discurso emancipador contra la violencia de género o machista ha contribuido a la inclusión en la legislación penal española de un tipo agravado de lesiones (Art. $148.4^{\circ} \mathrm{CP}$ ), fundamentada en una discriminación positiva de las mujeres frente a los hombres. Esta nueva figura delictiva ha generado importantes críticas en la doctrina penal por quebrantar el principio de igualdad y constituir una manifestación del derecho penal de

\footnotetext{
${ }^{87}$ Véase, la doctrina citada por MEYER, "Entre la teoría, el método", cit. nota no 49, p. 38.

${ }^{88}$ MEYER, "Entre la teoría, el método", cit. nota n 49 , pp. 38-39.

${ }^{89}$ MEYER, "Entre la teoría, el método", cit. nota no 49, p. 40.

${ }^{90}$ Sin bien, existen diferentes metodologías en el ACD que se sustenta en la tradición social empírica (la obtención de datos y el análisis), la mayoría se sitúan más en la hermenéutica que en el análisis deductivo por lo que se concentra más en los problemas y no en elementos específicos linguísticos. Respecto a los criterios para valorar la calidad de las investigaciones sustentadas en el análisis crítico del discurso no resulta posible aplicar sin modificaciones los conceptos clásicos de validez y factibilidad que se utilizan en la investigación cuantitativa. Ahora bien, el ACD, como toda manifestación del pensamiento crítico, debe ser de una alta calidad ya que ningún saber es objeto de tan feroces ataques debido a la supuesta falta de metodología. VAN DIJK, "La multidisciplinariedad", cit. nota ${ }^{\circ} 65$, pp. 144-153.
} 
autor. ${ }^{91}$ Como manifiesta el propio Van Dijk "después de todo, también los grupos dominados siguen sus propios intereses, en ocasiones contra todo pronóstico". 92

Pero quizá la crítica más interesante al ACD radica en la sobrevaloración del discurso a la hora de explicar las relaciones sociales, debido a que estos se forman en gran medida por medio del propio discurso. Sin embargo, continúa siendo problemático verificar en la práctica esta dependencia entre discurso y acciones sociales. Existe un vacío casi infranqueable entre lo que manifiesta la opinión pública y los medios de comunicación públicos sobre un determinado problema social y la realidad de las concretas acciones de los participantes en el discurso. Por esta razón, un enfoque cercano al ACD, denominado Análisis mediato del discurso (AMD), considera que las relaciones de poder en la sociedad no son única o esencialmente discursivas, sino que, por el contrario, están basadas en la práctica. Esto no significa que el AMD no tenga interés por el discurso. Al contrario, el AMD considera que una de sus principales tareas consiste en explicar y en comprender de qué modo se encuentra implicada o no la generalidad de los discursos en las acciones sociales que realizan los actores en su actividad cotidiana. Por tanto, el AMD no adopta el discurso como punto central de su interés, sino que entiende que la acción social se basa en la práctica (el hábito, el deseo, etc.) y no tanto en el análisis racional, lógico u objetivo. ${ }^{93}$ Como manifiesta Scollon "diga lo que diga la gente en sus acciones sociales y sobre ellas, no es probable que estos discursos aprehendan jamás las bases del hábito inductor de dichas acciones, ya que estas, en gran medida, quedan fuera de la conciencia de los actores". 94

\section{A modo de conclusión.}

El ACD constituye una provechosa herramienta analítica para comprender, desde una perspectiva crítica, el fenómeno de la criminalidad y el poder punitivo. $\mathrm{Su}$ aspecto más relevante radica en el análisis de las estructuras lingüísticas que son utilizadas para mantener las relaciones de dominación y desigualdad social.

Ahora bien, el ACD no debe considerarse como una nueva corriente criminológica, en el sentido de que tenga que competir con otras escuelas o corrientes, sino que constituye una perspectiva complementaria (la discursiva) a la criminología crítica. No obstante, la delincuencia y sus medios de control no han constituido una de las líneas fundamentales de investigación del ACD, cuando estamos ante unos de los ámbitos sociales donde los discursos reproducen con mayor intensidad la dominación y desigualdad social. No se ha elaborado una línea específica de investigación que analice, tanto desde una perspectiva general como específica, la incidencia del discurso en la etiología de la criminalidad y las

\footnotetext{
${ }^{91}$ Véase, BOLEA BARDON, Carolina, "En los límites del derecho penal frente a la violencia doméstica y de género", Revista Electrónica de Ciencia Penal y Criminología, RECPC09-02 (2007), pp.1-26. Las cuestiones de inconstitucionalidad planteadas por diversos juzgados ordinarios han sido rechazadas por las SSTC $41 \mathrm{y}$ $45 / 2010$.

92 VAN DIJK, "El análisis crítico", cit. nota no 2, p. 32.

${ }^{93}$ Véase, las coincidencias con Teoría criminológica de las Actividades Rutinarias.

94 SCOLLON, Ron, “Acción y texto: para una comprensión conjunta del lugar del texto en la (inter)acción social, el análisis mediato del discurso y el problema de la acción social” en: WODAK/MEYER (Comps.), Métodos de análisis crítico del discurso, cit. nota $\mathrm{n}^{\circ} 49$, p. 210.
} 
FERNÁNDEZ, José Ángel. “Análisis crítico del discurso y criminología.

Una aproximación interdisciplinar"

conductas desviadas y en los medios penales de control social. Los analistas críticos del discurso se han centrado en aspectos concretos. En términos criminológicos, ha incursionado en la victimología como, por ejemplo, en la violencia de género; o desarrollado análisis cercanos a la teoría del etiquetamiento, como la criminalización (discursiva) de la inmigración. ${ }^{95}$

Por esta razón, debemos animar a los analistas críticos del discurso a adentrarse en el estudio de la criminalidad y los medios penales de control social teniendo presente en sus análisis contextuales la vasta información que puede aportar la criminología. Y a contrario sensu propugnar por una criminología que incluya los análisis del discurso como una herramienta imprescindible para entender el fenómeno de la criminalidad y el poder punitivo. En una sociedad del riesgo determinada por una Nueva Era de la Información, la realidad discursiva debe constituir un aspecto central a considerar por parte de las ciencias penales.


Criminology,(2008), http://www.internetjournalofcriminology.com/Saint\%20$\% 20$ A $\%$ 20CRITICAL\%20DISCOURSE\%20ANALYSIS\%20OF\%20CORPORATE\%20ENVIRONMENTA L\%20HARM.pdf. O'BRIEN, E. L., Crime in verse. The poetics of murder in the Victorian era. Columbus: Ohio State University Press, 2008. SHUY, R. W., Language crimes. The use and abuse of language evidence in the Court Room. Oxford: Blackwell, 1992. CAVIGLIA, F., "Understanding public discourse about violence and crime: A challenge for critical discourse analysis at school", en: LASSEN, I., STRUNCK J., Strunck, \& VESTERGAARD, T., (Eds.), Mediating ideology in text and image: Ten critical studies, Amsterdam: John Benjamins Publishing Company, 2006. CUBELLS SERRA, J. e IÑIGUEZ RUEDA, L., "La construcción de hechos en el discurso jurídico: análisis del caso de 'Los robos en cajeros automáticos de la ciudad de Barcelona'”, Revista Española de Investigación Criminológica: REIC, 6, 2008. GILLIGAN, G. P. \& PRATT, J. (Eds.), Crime, truth and justice. Official inquiry, discourse, knowledge, Cullompton: Willan, 2004. RIGAKOS, G. S., "Risk Society and Actuarial Criminology: Prospects for a Critical Discourse", Canadian Journal of Criminology-Revue Canadienne de Criminologie, 1999. SASSON, T., Crime talk. How citizens construct a social problem. Hawthorne, N.Y.: Aldine de Gruyter, 1995. 
Polít. crim. Vol. 8, № 16 (Diciembre 2013), Art. 4, pp. 472-499.

[http://www.politicacriminal.cl/Vol_08/n_16/Vol8N16A4.pdf]

\section{BIBLIOGRAFÍA}

ALONSO, Luis Enrique y CALLEJO, Javier, "El análisis del discurso: del posmodernismo a las razones prácticas", Reus n ${ }^{\circ} 88$ (1999).

ARRIGO, B. y BERNARD, T., "Posmodern Criminology in Relation to Radical and Conflict Criminology", Critical Criminology n 8 (1997).

BENETT, Tony, "Theories of the media, theories of society", en: GUREVITCH et al, Culture, Society and the Media, London: Methuen, 1982.

BOLEA BARDON, Carolina, "En los límites del derecho penal frente a la violencia doméstica y de género", Revista Electrónica de Ciencia Penal y Criminología, RECPC09-02 (2007).

FAIRCLOUGH, Norman, "El análisis crítico del discurso como método de investigación de las ciencias sociales" en: WODAK, Ruth; MEYER, Michael (Comps.), Métodos de análisis crítico del discurso, Barcelona: Gedisa, (2003).

FAIRCLOUGH, Norman, "El análisis crítico del discurso y la mercantilización del discurso público: Las universidades", Discurso y Sociedad Vol. 2(1), 2008.

, Language and power, Londres: Longman, 1989.

, "Representaciones del cambio en el discurso neoliberal", Cuadernos de

Relaciones Laborales $\mathrm{n}^{\circ} 16$ (2000).

, "Políticamente correcto: la política de la lengua y la cultura", Sociedad y Discurso, GHIO, Elsa (trad.), Vol. 3(3), 2009.

FERNÁNDEZ CRUZ, José Ángel, "El juicio constitucional de proporcionalidad de las leyes penales: ¿la legitimación democrática como medio para mitigar su inherente irracionalidad?", Revista de Derecho Universidad Católica del Norte, Sección Estudios, Año 17- nº 1 (2010).

, "La legitimación ética de las leyes penales. Reflexiones desde la ética procedimental”, Revista de Derecho (Valdivia), Vol. XXII-no 2. (Diciembre 2009).

"Legitimación social de las leyes penales. Límites y ámbito de aplicación", Revista de Derecho Universidad Católica de Valparaíso XXXIII. Valparaíso, Chile, $2^{\circ}$ Semestre de 2009.

FISKE, John, "Los estudios culturales británicos y la televisión”, en: ALLEN, Robert (Ed.), LONGO, Fernanda (Trad.), Channels of discourse. Television and contemporary criticism. North Carolina: University of North Carolina Press, 1987, pp. 1-12. http://www.catedraa.com.ar/corporativa/archivos/FISKE-estudios-culturales.pdf

GLASGOW MEDIA GROUP: http://www.glasgowmediagroup.org/component/option,com_frontpage/Itemid,1/

HABERMAS, J., Conocimiento e interés, Madrid: Taurus, (1992).

HARCOURT, Bernard, "Meditaciones postmodernas sobre el castigo: acerca de los límites de la razón y de las virtudes de aleatoriedad (una polémica y un manifiesto)", Revista de Derecho Penal y Criminología n 90, Vol. XXXI (2010).

JÄGER, Siegfried, "Entre las culturas: caminos fronterizos en el análisis del discurso", Discurso y Sociedad, 2 (3), 2008.

LEA, J., "Criminology and postmodernity", en: WALTON \& YOUNG, J. (Eds.), The new criminology revisited, London: Macmillan, 1998.

MACNAIR, B. The Sociology of Journalism, Londrés: Arnold, 1998. 
FERNÁNDEZ, José Ángel. “Análisis crítico del discurso y criminología.

Una aproximación interdisciplinar"

MATTHEWS, Roger A., "The construction of 'So What?' criminology: a realist analysis", Crime, Law and Social Change 54 (2010).

MEYER, Michael, "Entre la teoría, el método y la política: la ubicación de los enfoques relacionados con el ACD", en: WODAK, Ruth; MEYER, Michael (Comps.), Métodos de análisis crítico del discurso, Barcelona: Gedisa (2003).

MILOVANOVIC, Dragan, "Postmodernism", en: McLAUGHLIN, Eugene; MUNCIE, John, (Eds.), The Sage Dictionary of Criminology, Sage Publications Ltd., $2^{\mathrm{a}}$ Ed., 2006.

PAVLICH, George, "Criticism and criminology: in search of legitimacy", Theoretical Criminology $\mathrm{n}^{\mathbf{o}} 3$ (1999).

RUGGIERO, Vincenzo y SOUTH, Nigel, "Green Criminology and Dirty Collar Crime", Criminal criminology vol.18, $\mathrm{n}^{\circ} 4$ (2010).

SCOLLON, Ron, "Acción y texto: para una comprensión conjunta del lugar del texto en la (inter)acción social, el análisis mediato del discurso y el problema de la acción social”, en: WODAK, Ruth; MEYER, Michael (Comps.), Métodos de análisis crítico del discurso, Barcelona: Gedisa, (2003).

SMART, Carol, "Feminist approaches to criminology or postmodern woman meets atavistic man", en: MORRIS, A., \& GELSTHOPE, L., (Eds.), Feminist perspectives in criminology, Milton Keynes: Open University Press, 1990.

TUPPER, Kenneth, "Drugs, discourses and education: a critical discourse analysis of high school drug education text", Discourse: Studies in the Cultural Politics of Education, vol.29, $\mathrm{n}^{\circ} 2$ (2008).

VAN DIJK, Teun A., "La multidisciplinariedad del análisis crítico del discurso: un alegato en favor de la diversidad", en: WODAK, Ruth; MEYER, Michael (Comps.), Métodos de análisis crítico del discurso, Barcelona: Gedisa, (2003). , "Critical Discourse Analysis", en: TANNEN, D.; SCHIFFRIN, D.; HAMILTON, H. (Eds.), Handbook of Discourse Analysis, Oxford: Blackwell, 2001. ,"El análisis crítico del discurso", Anthropos n 186, septiembre-octubre 1999. , "Algunos principios de una teoría del contexto", Revista latinoamericana de estudios del discurso $\mathrm{n}^{\circ} 1$ (2001).

, Sociedad y discurso: cómo influyen los contextos sociales sobre el texto y la conversación, Barcelona: Gedisa, 2011.

VATINO, G., "Prólogo" en: MESSUTI, A., La Justicia deconstruida, Barcelona: Bellaterra, (2008).

WHITE, Rob y HAINES, Fiona, Crime and Criminology. An introduction, $3^{\mathrm{a}}$ ed., Oxford: Oxford University Press, 2004.

WODAK, Ruth, "De qué trata el análisis crítico del discurso (ACD) - Resumen de su historia, sus conceptos fundamentales y sus desarrollos" en: WODAK, Ruth; MEYER, Michael (Comps.), Métodos de análisis crítico del discurso, Barcelona: Gedisa, (2003).

YVONNE, Jewkes, Media \& Crime, 2ª ed., Sage Publications Ltd., 2011. 